\title{
Resíduos da indústria de filetagem de tilápia do Nilo (Oreochromis niloticus) na forma de farinhas e silagem para a alimentação de lambari (Astianax bimaculatus)
}

\author{
Use of industrial waste filleting of Nile tilapia (Oreochromis niloticus) in the \\ form of flour and corn silage for feeding lambari (Astyanax bimaculatus)
}

Wilson Rogério Boscolo ${ }^{[a]}$, Aldi Feiden ${ }^{[b]}$, Arcângelo Augusto Signor ${ }^{[c]}$, Sidnei Klein ${ }^{[d]}$, Fábio Bittencourt ${ }^{[e]}$, Arlindo Fabrício Corrêia ${ }^{[f]}$

[a] Zootecnista, doutor, professor adjunto da Universidade Estadual do Oeste do Paraná (Unioeste), Câmpus Toledo, Toledo, PR - Brasil, e-mail:wrboscolo@unioeste.br

[b] Engenheiro-agrônomo, doutor, professor adjunto da Universidade Estadual do Oeste do Paraná (Unioeste), Câmpus Toledo, Toledo, PR - Brasil, e-mail: aldi@unioeste.br

[c] Engenheiro de pesca, doutor, professor assistente do Instituto Federal do Paraná (IFPR), Câmpus de Foz do Iguaçu, PR - Brasil, e-mail: angelo_signor@hotmail.com

[d] Engenheiro de pesca, doutorando em Zootecnia na Universidade Estadual de Maringá (UEM), Câmpus de Maringá, Toledo, PR - Brasil, e-mail: skpesca@hotmail.com

[e] Zootecnista, doutorando em Aquicultura na Universidade Estadual Paulista (Unesp), Câmpus de Jaboticabal, Toledo, PR Brasil, e-mail, bitanca@hotmail.com

[f] Engenheiro-agrônomo, mestrando em Energia na Agricultura, Universidade Estadual do Oeste do Paraná (Unioeste), Câmpus de Cascavel, Toledo, PR - Brasil, e-mail: afcorreia.pr@gmail.com

\section{Resumo}

O trabalho objetivou avaliar a inclusão de resíduos da indústria de filetagem de tilápias do Nilo (Oreochromis niloticus) na forma de farinha (FT) e silagem (SR) na alimentação de lambari (Astianax bimaculatus). Foram utilizados 100 alevinos de lambari, com peso inicial de $0,087 \pm 0,006$ g, distribuídos em 20 aquários com capacidade de $30 \mathrm{~L}$, em um delineamento experimental inteiramente casualizado com quatro tratamentos e cinco repetições. A ração-controle foi formulada a base de milho, farelo de soja e farelo de trigo, sem inclusão de alimentos de origem animal e os outros três tratamentos apresentaram a inclusão de resíduos da indústria de filetagem de tilápia como fonte de proteína de origem animal: FT (100\%); SR (100\%); FT (50\%) + SR (50\%). 0 arraçoamento foi realizado quatro vezes ao dia, na forma farelada e à vontade durante 32 dias. Os parâmetros físicos e químicos da água como $\mathrm{pH}$, condutividade elétrica $(\mathrm{mS} / \mathrm{cm})$ e oxigênio dissolvido $(\mathrm{mg} / \mathrm{L})$ foram medidos semanalmente, enquanto que a temperatura $\left({ }^{\circ} \mathrm{C}\right)$ foi monitorada diariamente às $8 \mathrm{~h}$ e às $17 \mathrm{~h}$. Os parâmetros zootécnicos avaliados nos lambaris foram peso final médio, ganho de peso médio, comprimento final médio, conversão alimentar aparente, sobrevivência e fator de condição. Não houve diferenças significativas entre os tratamentos para os parâmetros zootécnicos avaliados $(p>0,05)$. Conclui-se que tanto a FT como a SR podem ser utilizadas conjuntamente ou de maneira distinta em rações para alevinos de lambari sem causar prejuízo no desempenho dos animais.

Palavras-chave: Desempenho produtivo. Ração. Subprodutos. 


\section{Abstract}

The study was performed to evaluate the inclusion of waste from Nile tilapia (Oreochromis niloticus) filleting process in the form of flour (FT) and silage (SR) as lambari feed (Astyanax bimaculatus). A total of 100 lambari with an initial weight of $0.087 \pm 0.006 \mathrm{~g}$ were used, distributed in 20 tanks with $30 \mathrm{~L}$ capacity and in a completely randomized design with four treatments and five repetitions. The control diet was formulated based on corn, soybean bran and wheat bran, without the inclusion of foods from animal origin, whereas the other three treatments presented the inclusion of industrial waste from tilapia filleting as a source of animal protein: FT (100\%), SR (100\%) and FT (50\%) + SR (50\%). Fish were fed four times a day in mash form for 32 days. The physico-chemical parameters of water, such as $\mathrm{pH}$, electrical conductivity $(\mathrm{mS} / \mathrm{cm})$ and dissolved oxygen $(\mathrm{mg} / \mathrm{L})$ were measured weekly, while the temperature $\left({ }^{\circ} \mathrm{C}\right)$ was monitored daily at 8:00 and 17:00. The parameters evaluated in lambaris were the average final weight, weight gain, average final length, feed conversion rate, survival and condition factor. The results showed no significant differences among treatments for all parameters evaluated ( $p>0.05)$. Therefore, both the FT and the SR diets can be used to feed lambari fingerlings without affecting the performance of the animals.

Keywords: Productive performance. Feed. Subproducts.

\section{Introdução}

O lambari (Astyanax bimaculatus) é um Characidae de pequeno porte, e muito comum em rios brasileiros, sendo cultivado em tanques e com potencial para a piscicultura (HAYASHI et al., 2002; HAYASHI et al., 2004). Nos últimos anos, busca-se sua produção em escala comercial para o consumo como petisco e como isca para a pesca esportiva (SOARES et al., 1999; FEIDEN et al., 2005a).

Segundo Carvalho et al. (2001), esta espécie apresenta algumas características importantes para o cultivo intensivo, pois possui hábito alimentar onívoro, aceita alimentação com rações artificiais, é de fácil obtenção de alevinos, carne de excelente paladar e atinge o tamanho comercial com três meses de idade. Hayashi et al. (1999) determinaram a exigência de proteína bruta (PB) para alevinos de lambari (A. bimaculatus) e observaram efeito quadrático entre 28 e $40 \%$ de $\mathrm{PB}$, com melhores resultados para $36,43 \%$ de PB.

Nos últimos anos, o processo de industrialização de peixes aumentou consideravelmente com as indústrias de beneficiamento que visam principalmente à filetagem (UCCI, 2003). De acordo com Vidotti et al. (2003), grandes quantidades de peixes são desperdiçadas durante a captura, comercialização e processos industriais, e, ainda, segundo Boscolo et al. (2001) e Boscolo (2003), o volume de descarte durante o processo de filetagem de tilápias chega a $65 \%$ da matéria-prima. Fazem parte dos resíduos do processamento de peixes: cabeça, nadadeiras, pele e vísceras que, dependendo da espécie, podem chegar a $66 \%$ em relação ao seu peso total (CONTRERAS-GUZMÁN, 1994). Esse resíduo apresenta grande quantidade de proteína, podendo ser uma alternativa para a alimentação animal.

A farinha de resíduo da indústria de filetagem de tilápias (FT) e a silagem de resíduos da indústria de filetagem de tilápias (SR) são alternativas viáveis para o aproveitamento dos resíduos, sendo vários os trabalhos que comprovam a eficiência da FT na alimentação de organismos aquáticos (BOSCOLO, 2005a, b; FEIDEN et al., 2005c; ISHIDA et al., 2004; SIGNOR et al., 2004). No entanto, para que a elaboração de farinhas seja economicamente viável, a produção de resíduos deve ser superior a 10 ton/dia (UCCI, 2003).

Por sua vez, a preparação da silagem apresenta custo reduzido, por se tratar de um processo simples e acessível à produção em pequena escala, além de não exigir mão de obra especializada, não envolver altos custos com energia e equipamentos, necessitando apenas de um triturador, agitador e recipientes plásticos (UCCI, 2003).

Segundo Ogawa e Maia (1999), a produção de silagem não exala odores desagradáveis que poderiam ocasionar problemas ambientais de poluição do ar, não atrai insetos, como moscas, e nem 
apresenta problemas com patógenos, como salmonela (BOSCOLO et al., 2010). Contudo, considerando as desvantagens, o produto é volumoso, de difícil transporte e estocagem e no caso de pescados tropicais, o alto teor de gorduras pode complicar o preparo da silagem e até prejudicar o produto, por causa da possibilidade de oxidação (OETTERER, 1994).

Pereira et al. (2002) recomendam a utilização de no máximo 30\% de silagem de peixe substituindo a ração comercial, sem causar prejuízo para alevinos de tilápia do Nilo.

0 objetivo do presente trabalho foi avaliar a inclusão da farinha (FT) e da silagem ácida de resíduos da indústria de filetagem de tilápias (SR) em rações para alevinos de lambari (A. bimaculatus).

\section{Materiais e métodos}

O presente experimento foi realizado no Laboratório de Aquicultura da Universidade Estadual do Oeste do Paraná, Câmpus Toledo, por um período de 32 dias. Foram utilizados 100 alevinos de lambari, apresentando peso e comprimento inicial médio de $0,087 \pm 0,006$ g e $1,88 \pm 0,20 \mathrm{~cm}$, respectivamente, distribuídos em 20 aquários com capacidade volumétrica de $30 \mathrm{~L}$. Um delineamento experimental inteiramente casualizado com quatro tratamentos e cinco repetições, em que o tratamento 1 representou ração com inclusão de farinha de tilápia; o tratamento 2 , ração com $50 \%$ de inclusão de farinha de tilápia e $50 \%$ de silagem ácida de resíduos da indústria da filetagem de tilápias; e o tratamento 3 , ração com silagem ácida de resíduos da indústria da filetagem de tilápias. Todas as inclusões foram tomadas como fonte proteica de origem animal, mas no tratamento 4 , a ração controle era a que não continha inclusão de alimentos de origem animal. A unidade experimental era constituída por um aquário com cinco alevinos, com aeração constante por meio de um sistema conectado a um soprador de ar central.

A SR foi preparada a partir de resíduos da indústria de filetagem de tilápias, sendo que tais resíduos foram triturados e misturados com adição de 5\% de ácido acético e posteriormente armazenados por 60 dias em galões plásticos até adequada acidificação deles. A escolha do ácido acético para acidificação deveu-se ao baixo risco no manuseio desse ácido orgânico. 0 pH da silagem ao fim de 60 dias foi de 4,75 e para a sua neutralização utilizou-se 3,5\% de cal hidratada. Para a formulação das rações, os alimentos foram moídos em um moinho tipo faca com peneira de malha $0,5 \mathrm{~mm}$ e posteriormente misturados, apresentando a mesma granulometria em todos os tratamentos. As rações foram isoenergéticas apresentando $3493 \mathrm{kcal} / \mathrm{kg}$ de energia digestível, e isoproteicas com 33\% de proteína. As composições percentuais e químicas das rações experimentais estão apresentadas na Tabela 1 . A farinha de resíduos foi preparada por cocção, prensagem e moagem, segundo Boscolo e Feiden (2007).

Tabela 1 - Composição percentual e química das rações experimentais com silagem ácida na dieta de alevinos de lambari

\begin{tabular}{|c|c|c|c|c|}
\hline \multirow{4}{*}{ Ingredientes (\%) } & \multicolumn{4}{|c|}{ Tratamentos } \\
\hline & 1 & 2 & 3 & 4 \\
\hline & \multicolumn{3}{|c|}{ Inclusão de silagem (\%) } & \multirow{2}{*}{ Controle vegetal } \\
\hline & 0 & 50 & 100 & \\
\hline Antioxidante - BHT & 0,020 & 0,020 & 0,020 & 0,020 \\
\hline Calcário calcítico & - & - & - & 2,253 \\
\hline Fosfato bicálcico & - & - & - & 3,124 \\
\hline Farelo de soja & 31,416 & 32,407 & 33,399 & 56,817 \\
\hline Farinha de tilápia & 20,000 & 10,000 & - & - \\
\hline Silagem ácida & - & 10,000 & 20,000 & - \\
\hline Farelo de trigo & 34,271 & 34,676 & 35,081 & 17,939 \\
\hline Milho & 10,000 & 10,000 & 10,000 & 10,000 \\
\hline Óleo de soja & 2,793 & 1,397 & - & 8,346 \\
\hline Suplemento (min. vit.)* & 1,000 & 1,000 & 1,000 & 1,000 \\
\hline Sal & 0,50 & 0,50 & 0,50 & 0,50 \\
\hline Total & 100 & 100 & 100 & 100 \\
\hline
\end{tabular}


Tabela 1 - Composição percentual e química das rações experimentais com silagem ácida na dieta de alevinos de lambari

(CONCLUSÃO)

\begin{tabular}{lcccc}
\hline & \multicolumn{4}{c}{ Tratamentos } \\
\cline { 2 - 4 } Ingredientes (\%) & $\mathbf{1}$ & $\mathbf{2}$ & $\mathbf{3}$ & $\mathbf{4}$ \\
\cline { 2 - 4 } & \multicolumn{1}{c}{ Nutrientes (\%) } & Controle vegetal \\
\cline { 2 - 4 } & 3493 & $\mathbf{5 0}$ & $\mathbf{1 0 0}$ & 3493 \\
Energia digestível & 33,00 & 3493 & 3493 & 33,00 \\
Proteína bruta & 1,704 & 33,00 & 33,00 & 1,710 \\
Cálcio & 1,127 & 1,707 & 1,710 & 1,148 \\
Fósforo-total & 9,520 & 1,137 & 1,148 & 10,165 \\
Gordura & & 9,355 & 9,189 & \\
\hline
\end{tabular}

Legenda: 1 = Ração com inclusão de farinha de tilápia como fonte proteica de origem animal; 2 = Ração com 50\% de inclusão de farinha de tilápia e $50 \%$ de silagem ácida de resíduos da indústria da filetagem de tilápias como fonte proteica de origem animal; 3 = Ração com 100\% de silagem ácida de resíduos da indústria da filetagem de tilápias como fonte proteica de origem animal; 4 = Ração sem inclusão de alimentos de origem animal.

Fonte: Dados da pesquisa.

Nota: Níveis de garantia por quilograma do produto (Rovimix peixes):Vit.A,500.000 Ul;Vit.D3,200.000 Ul;Vit.E,5.000 mg;Vit.K3,1.000 mg;Vit.B1,1.500 mg;Vit.B2, 1.500 mg; Vit. B6, 1.500 mg; Vit. B12, 4.000 mg; Ác. Fólico, 500 mg; Pantotenato Ca, 4.000 mg; Vit. C, 15.000 mg; Biotina, 50 mg; Inositol, 10.000; Nicotinamida, 7.000; Colina, 40.000 mg; Co, 10 mg; Cu, 500 mg; Fe, 5.000 mg; I, 50 mg; Mn, 1500 mg; Se, 10 mg; Zn, 5.000 mg.

As rações foram fornecidas na forma farelada, até a saciedade aparente, quatro vezes ao dia, às $8 \mathrm{~h}$, $11 \mathrm{~h}, 14 \mathrm{~h}$ e $17 \mathrm{~h}$. Diariamente foi realizada a sifonagem dos aquários para a remoção das fezes e sobras de rações, com retirada e reposição de $40 \%$ do volume de água, pela manhã e à tarde. Os parâmetros físicos e químicos como oxigênio dissolvido ( $\mathrm{mg} / \mathrm{L}$ ), $\mathrm{pH}$, condutividade elétrica $(\mathrm{mS} / \mathrm{cm})$, foram medidos semanalmente, enquanto que a temperatura $\left({ }^{\circ} \mathrm{C}\right)$ foi monitorada diariamente antes da primeira e última alimentação.
Ao término do experimento, os animais de cada unidade experimental foram pesados e medidos para avaliação do peso final médio, ganho de peso médio, comprimento final médio, conversão alimentar aparente, sobrevivência e fator de condição obtido por meio da expressão $\left(\left(\mathrm{wt} / \mathrm{lt}^{3}\right) \times 100\right)$, conforme descrito por Vazzoler e Vazzoler (1965). Os dados obtidos foram submetidos à análise de variância ao nível de 5\% de significância pelo programa estatístico SAEG - Sistema de Análises Estatísticas e Genéticas (UFV, 1997).

Quadro 1 - Desempenho produtivo dos alevinos de lambari (A. bimaculatus) alimentados com silagem ácida e farinha de tilápia de resíduos da indústria de filetagem de tilápias

\begin{tabular}{|c|c|c|c|c|c|}
\hline \multirow{2}{*}{ Parâmetros* } & \multicolumn{4}{|c|}{ Rações com inclusão de silagem } & \multirow{2}{*}{$\mathrm{CV}(\%)$} \\
\hline & 1 & 2 & 3 & 4 & \\
\hline Peso inicial (g) & $0,087 a$ & $0,087 a$ & $0,087 a$ & $0,087 a$ & \\
\hline Peso final $(g)$ & $1,896 a$ & $1,999 a$ & $2,213 a$ & $1,880 \mathrm{a}$ & 15,037 \\
\hline Ganho de peso (g) & $1,800 \mathrm{a}$ & $1,912 \mathrm{a}$ & $2,127 a$ & $1,793 a$ & 15,708 \\
\hline Comprimento final (cm) & $4,764 a$ & $4,488 \mathrm{a}$ & $5,040 \mathrm{a}$ & $4,826 a$ & 8,848 \\
\hline Sobrevivência (\%) & $95 a$ & $100 \mathrm{a}$ & $96 a$ & $95 a$ & 8,386 \\
\hline Conversão alimentar aparente(g) & $2,888 a$ & $2,372 a$ & $2,120 \mathrm{a}$ & $2,812 a$ & 17,860 \\
\hline Fator de condição(g/g) & $1,713 a$ & $1,456 a$ & $1,748 a$ & $1,676 a$ & 30,267 \\
\hline
\end{tabular}

Legenda: ${ }^{*}=(p>0,05) ; 1$ = Ração com inclusão de farinha de tilápia como fonte proteica de origem animal; 2 = Ração com 50\% de inclusão de farinha de tilápia e $50 \%$ de silagem acida de resíduos da indústria da filetagem de tilápias como fonte proteica de origem animal; 3 = Ração com $100 \%$ de silagem ácida de resíduos da indústria da filetagem de tilápias como fonte proteica de origem animal; 4 = Ração sem inclusão de alimentos de origem animal .

Fonte: Dados da pesquisa. 


\section{Resultados}

Os parâmetros físicos e químicos da água permaneceram dentro da faixa recomendada por Boyd (1990) e Sipaúba-Tavares (1995) para peixes de clima tropical, com valores de 5,13 $\pm 0,32 \mathrm{mg} / \mathrm{L} ; 7,61 \pm$ 0,30 e $92,15 \pm 1,72 \mathrm{mS} / \mathrm{cm} ; 27,35 \pm 0,78^{\circ} \mathrm{C}$, para oxigênio dissolvido, $\mathrm{pH}$, condutividade elétrica e temperatura, respectivamente.

As médias das variáveis de peso final (PF), ganho de peso (GP), comprimento final (CF), sobrevivência (SO), conversão alimentar aparente (CA) e fat de condição (FC) estão apresentadas no Quadro 1, demonstrado anteriormente.

\section{Discussão}

Os resultados observados neste experimento são semelhantes aos obtidos por Feiden et al. (2005a) para o lambari, ao não observarem diferença significativa $(p>0,05)$ no desempenho produtivo, sobrevivência e conversão alimentar dos animais alimentados com dietas com inclusão de 0, 5, 10 e 15\% de farinha de resíduos da indústria de filetagem de tilápias (FT). Um baixo índice de conversão alimentar ou sofríveis valores de conversão alimentar também foram observados por esses autores, e podem estar relacionados com a forma de alimentação, pois a ração farelada provoca elevadas perdas na água, não sendo totalmente aproveitada pelos peixes (FEIDEN et al., 2005a).

Ramos et al. (1994) não observaram diferença no GP de alevinos de tambaqui (Colossoma macropomum) alimentados com dietas contendo diferentes níveis de inclusão de silagem de peixe. Nesse sentido, Vidotti et al. (2002) não observaram diferença no PF e CA de alevinos de pacu (Piaractus mesopotamicus) alimentados com silagem pré-cozida de pescado em substituição à farinha de peixe. Resultados contrários foram observados por Signor et al. (2003) para a carpa comum, com melhores valores/médias de GP para os peixes que receberam dietas contendo $5 \%, 7,5 \%$ e $10 \%$ de inclusão de silagem de peixe, sendo que a melhor taxa de CA foi obtida no tratamento de $2,5 \%$ de inclusão, diferindo dos tratamentos que substituíram a farinha de peixe pela silagem de peixe em níveis de 7,5 e 10\%. Fagbenro e Jauncey (1995) observaram menor ganho de peso para o bagre africano, alimentado com rações contendo silagem ácida na dieta, não verificando diferença na CA.

Boscolo et al. (2005b), trabalhando com FT na dieta da tilápia do Nilo, constataram que níveis de até 20,0\% de inclusão de FT para larvas e até $13,52 \%$ de inclusão de FT em rações para alevinos não afetam o desempenho e a sobrevivência dos animais. Boscolo et al. (2005a), também obtiveram melhora no desempenho de alevinos de piavuçu (Leporinus macrocephalus), sendo que, para essa espécie, a taxa de inclusão de FT de 8,19\% apresentou a melhor conversão alimentar.

Feiden et al. (2005b) e Feiden et al. (2005c) não observaram diferença nos parâmetros de desempenho produtivo avaliados para a carpa comum e para alevinos de tilápia do Nilo, com dietas contendo níveis de 0 a $15 \%$ de FT e $0 \% \mathrm{FT}+0,08 \%$ de metionina sintética (Dl-metionina 99\%), resultando em 0,55\% em metionina total, e relatam que a suplementação de metionina sintética não se mostrou eficiente para as espécies avaliadas.

Carvalho et al. (2006) estudaram a composição química da silagem de resíduos de peixe acrescida de $30 \%$ de farelo de trigo e o desempenho de alevinos de tilápia do Nilo, recebendo níveis de 0, 10, 20 e $30 \%$ da silagem na dieta. Foi verificado que os resíduos processados como silagem e adicionados em $30 \%$ de farelo de trigo, resultaram em rações com boa qualidade e com potencial para utilização na alimentação de alevinos de tilápia do Nilo promovendo redução no custo de alimentação.

Vidotti (2001) avaliou silagens com três tipos de resíduos (descartes da comercialização de peixes marinhos inteiros; descartes de peixes de água doce inteiros e resíduos da filetagem de tilápias) e concluiu que todas as silagens analisadas podem substituir a farinha de peixe, sem promover diferenças no desenvolvimento de alevinos de pacu (P. mesopotamicus).

Por apresentar hábito alimentar onívoro, o lambari (A. bimaculatus) digere e absorve com maior eficiência ingredientes tanto de origem animal quanto vegetal, explicando a ausência de diferença nos tratamentos (KUBARIK, 1997; TENGJAROENKUL et al., 2000). Os resultados observados no presente estudo demonstram que o emprego de silagem ácida e de farinha de tilápia de resíduos da indústria de filetagem de tilápias não diferiu da dieta com ingredientes de fontes vegetais. Portanto, para a criação de lambaris, podem 
ser utilizadas as três fontes proteicas avaliadas sem proporcionar diferenças no desempenho zootécnico. Assim, conforme a oferta e o custo regionalizado dos insumos, pode-se formular a dieta objetivando elevar a rentabilidade da criação de lambari, especialmente para pequenos produtores que tenham disponibilidade de resíduos, possam utilizar essas fontes em uma pequena escala de produção.

\section{Conclusão}

A silagem ácida de resíduos de filetagem de tilápia do Nilo e a farinha de resíduos da indústria de filetagem de tilápias podem ser incluídas na dieta dos alevinos de lambari (A. bimaculatus) sem acarretar prejuízo no desempenho zootécnico dos animais.

\section{Referências}

BOSCOLO, W. R. et al. Desempenho e características de carcaça de machos revertidos de tilápias do Nilo (Oreochromis niloticus), linhagens tailandesa e comum, nas fases iniciais e de crescimento. Revista Brasileira de Zootecnia, v. 30, n. 5, p. 1391-1396, 2001.

BOSCOLO, W. R. Farinha de resíduos da indústria de filetagem de tilápia na alimentação da tilápia do Nilo Oreochromis niloticus. 2003. 83 f. Tese de Doutorado. (Pós-graduação em Zootecnia), Universidade Estadual de Maringá, Maringá, PR, 2003.

BOSCOLO, W. R. et al. Farinha de Resíduos da Filetagem de Tilápia em Rações para Alevinos de Piauçu (Leporinus macrocephalus). Revista Brasileira de Zootecnia, v. 34, n. 6, p. 1819-1827, 2005a.

BOSCOLO, W. R. et al. Farinha de Resíduos da Filetagem de Tilápias na Alimentação de Tilápia-do-Nilo (Oreochromis niloticus) na Fase de Reversão Sexual. Revista Brasileira de Zootecnia, v. 34, n. 6, p. 1807-1812, 2005b.

BOSCOLO, W. R. et al. FEIDEN, A. Industrialização de tilápias. Toledo: GFM Gráfica \& Editora, 2007.

BOSCOLO, W. R. et al. Avaliação microbiológica e bromatológica da silagem ácida obtida de resíduos da indústria de filetagem de tilápia do Nilo (Oreochromis niloticus). Revista Semina, v. 31, n. 2, p. 515-522, abr./jun. 2010.
BOYD, C. Water quality in ponds for aquaculture. London: Birmingham Publishing Co., 1990.

CARVALHO, G. G. P. et al. Silagem de resíduo de peixes em dietas para alevinos de tilápia do nilo. Revista Brasileira de Zootecnia, v. 35, n. 1, 2006.

CARVALHO, R. L.; PÁDUA, D. M. C.; PÁDUA, J. D. Avaliação econômica da criação de lambari (Astianax bimaculatus) em tanques rede In: REUNIÃO ANUAL DA SOCIEDADE BRASILEIRA DE ZOOTECNIA, 38., 2001, Piracicaba. Anais... Piracicaba: Sociedade Brasileira de Zootecnia, 2001.

CONTRERAS-GUZMÁN, E. Bioquímica de pescados e derivados. Jaboticabal: FUNEP, 1994.

FAGBENRO, 0.; JAUNCEY, K. Growth and protein utilization by juvenile catfish (Clarias gariepinus) fed dry diets containing co-dried lactic-acid-fermented fish-silage and protein feedstuffs. Bioresource Technology, v. 51, p. 29-35, 1995.

FEIDEN, A. et al. Uso da farinha de resíduo da filetagem de tilápia na alimentação de alevinos de lambari (Astyanax bimaculatus) In: REUNIÃO ANUAL DA SOCIEDADE BRASILEIRA DE ZOOTECNIA, 42., Goiânia. Anais... Goiânia: Sociedade Brasileira de Zootecnia, 2005a. CD-ROM.

FEIDEN, A. et al. Farinha de resíduos da filetagem de tilápia na dieta de alevinos de carpa comum (Cyprinus carpio). In: REUNIÃO ANUAL DA SOCIEDADE BRASILEIRA DE ZOOTECNIA, 42., Goiânia. Anais... Goiânia: Sociedade Brasileira de Zootecnia, 2005b, CD-ROM.

FEIDEN, A. et al. Farinha de resíduos da filetagem de tilápia em rações para alevinos de tilápia do Nilo Oreochromis niloticus. Revista Semina, v. 26, n. 2, p. 249-255, 2005c.

HAYASHI, C. et al. Efeito do número diário de arraçoamento sobre o desempenho de alevinos de lambari (Astyanax bimaculatus), In: SIMPÓSIO BRASILEIRO DE AQUICULTURA, 12., 2002, Goiânia. Anais... Goiânia: Simpósio Brasileiro de Aquicultura, 2002.

HAYASHI, C. et al. Frequência de arraçoamento para alevinos de lambari do rabo-amarelo (Astyanax bimaculatus). Revista Brasileira de Zootecnia, v. 33, n. 1, p. 21-26, 2004.

HAYASKI, C. et al. In: REUNIÃO ANUAL DA SOCIEDADE BRASILEIRA DE ZOOTECNIA, 36., 1999, Porto Alegre. Anais... Porto Alegre: Sociedade Brasileira de Zootecnia, 1999. CD-ROM. 
ISHIDA, F. A.; FEIDEN, A.; SIGNOR, A.; BOSCOLO, W. R.; SIGNOR, A. A.; BOMBARDELLI, R. A. Uso da Farinha de Resíduo de Indústrias de Filetagem de Tilápias na Alimentação de Alevinos de Curimbatá. In: II SIMPÓSIO PARANAENSE DE ENGENHARIA DE PESCA, VI SEMANA ACADÊMICA DE ENGENHARIA DE PESCA, Toledo, PR, 2004.

KUBARIK, J. Tilapia on highly flexible diets. Feed International, v. 6, p. 16-18, 1997.

OETTERER, M. Produção de silagem a partir de biomassa residual de pescado. Alimento e Nutrição, v. 5, p.119--135, 1994.

OGAWA, M.; MAIA, E. L. Manual de pesca: ciência e tecnologia do pescado. São Paulo: Varela, 1999. v. 1

PEREIRA, C. A. R. et al. Utilização de silagem biológica de peixe em substituição a uma ração comercial na alimentação de alevinos de Tilápia. In: XXXIX SEMINÁRIO BRASILEIRO DE ZOOTECNIA, Pernambuco, 2002.

RAMOS, V. O. et al. Ensayo sobre la alimentación de la cachama negra (Colossoma macropomum) con pescado almacenado y preservado en ácidos orgánico e inorgánico (Fish silage). Boletin Científico INPA, n. 2, p. 46-59, 1994.

SIGNOR, A. et al. A. Farinha de Resíduos da Filetagem de Tilápia em Rações para Alevinos de Tilápia do Nilo Oreochromis niloticus. In: REUNIÃO ANUAL DA SOCIEDADE BRASILEIRA DE ZOOTECNIA, 41., 2004, Campo Grande. Anais... Campo Grande.: Sociedade Brasileira de Zootecnia, 2004. v. 41

SIGNOR, A. et al. Silagem de peixes na alimentação de alevinos de carpa comum Cyprinus carpio. I SIMPÓSIO PARANAENSE DE ENGENHARIA DE PESCA E V SEMANA ACADÊMICA DE ENGENHARIA DE PESCA, EDUNIOESTE, Toledo, PR, 2003.

SIPAÚBA-TAVARES, L. H. S. Limnologia aplicada à aquicultura. Jaboticabal: Funet, 1995.

SOARES, C. M. et al. Substituição parcial da proteína da farinha de peixe pela de fontes proteicas alternativas em dietas para alevinos de lambari (Astyanax bimaculatus). In: REUNIÃO ANUAL DA SOCIEDADE BRASILEIRA DE ZOOTECNIA, 36., 1999, Porto Alegre. Anais... Porto Alegre: Sociedade Brasileira de Zootecnia, 1999. CD-ROM.
TENGJAROENKUL, B. et al. Distribution of intestinal enzyme activities along the intestinal tract of cultured Nile tilapia, Oreochromis niloticus L. Aquaculture, 2000. 182:317-327.

UCCI, P. Desenvolvimento de silagem ácida a partir de resíduos da filetagem de tilápias (Oreochromis niloticus) utilizando diferentes ácidos. 2003.27 f. Monografia. (Curso de Engenharia de Pesca) - Universidade Estadual do Oeste do Paraná. Toledo, 2003.

UNIVERSIDADE FEDERAL DE VIÇOSA. UFV. 1997. SAEG Sistema para análises estatísticas e genéticas. Versão 7.1. Viçosa, MG.150 p. (Manual do usuário).

VAZZOLER, A. E. A. M.; VAZZOLER, G. Relation between condiction factor and sexual development in Sardinella aurita. Academia Brasileira de Ciências, v. 37, p. 353 $359,1965$.

VIDOTTI, R. M. et al. Growth Rate of Pacu, Piaractus mesopotamicus, Fingerlings Fed Diets Containing Co-Dried Fish Silage as Replacement of Fish Meal. Journal-ofApplied-Aquaculture, v. 12, n. 4, p. 77-88, 2002.

VIDOTTI, R. M.; VIEGAS, E. M. M.; CARNEIRO, D. J. Amino acid composition of processed fish silage using different raw materials. Universidade de São Paulo, Pirassununga, PR, 2003.

VIDOTTI, R. M. Produção e utilização de silagens de peixe na nutrição do pacu (Piaractus mesopotamicus), Jaboticabal, 2001. p. 50-57. Tese de doutoradoUniversidade Estadual Paulista Centro de Aquicultura, Câmpus de Jaboticabal, 2001.

Recebido: 28/07/2012

Received: 07/28/2012

Aprovado: $23 / 10 / 2012$

Approved: 10/23/2012 